\title{
Fashion and Death Ethnographic Explorations on Ubiquitous Styles
}

\author{
Massimo Canevacci* \\ University of Rio de Janeiro UERJ, Brazil
}

Submission: February 12, 2018; Published: October 03, 2018

*Corresponding author: Massimo Canevacci, University of Rio de Janeiro UERJ, Brazil, Email: maxx.canevacci@gmail.com

Abstract

My anthropological glance will focus one a fashion shows in Rio de Janeiro and a "passista" carioca in the carnival 2011; a Karl Lagerfeld's fetish design (body-corpse); a bizarre mannequin I met in Belem (Brazil). I'll try to demonstrate the deep connection between living body and death corpse in a meta-fetishist perspective and - by the meta-morphic dialogue written by Giacomo Leopardi - on fashion and death (Figure 1).

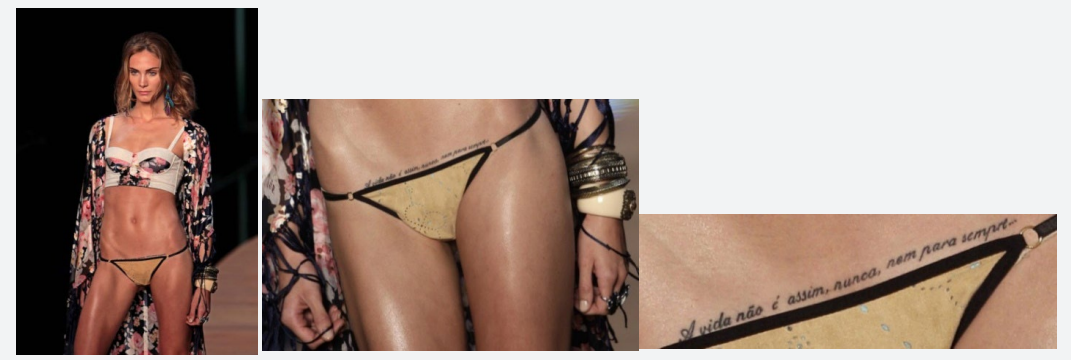

Figure 1: Coca Cola Clothing, Thais Rossiter fashion designer, Fashion Rio.

\section{Fashion Rio}

The model is stationary, as a doll-like, in the sense of "dollifyng" her body: an empty gaze directed towards nothing, both arms inert by her side, her legs in a hopelessly waiting. The trained eroptic (8) eye targets her without hesitation, not so much the bikini, but what is tattooed just above her pubis: a vida não é assim, nunca, para nem para sempre ('life is not like this, never and even less for ever'). A philosophical statement presented by fashion as a reflective affirmation of itself. A meta-communication of the profound meaning of 'what' is actually fashion. Rio's designer is a philosopher as much as Zaha Hadid. Philosopher in both, the show composition and the public / pubic text tattooed for the observer's sexualized eyes. From this 'eroptic' dimension, I offer two reflections based on dialogues with two poets-essayists, Horace and Leopardi [1].

\section{Horace}

The Roman poet known for his proposition on time that, in the unsurpassed simplicity of the Latin language, offers an oblique perspective through which time can be observed. Indeed, a time that is not only Kronos, as the Greek masters taught, but also Kairos: a nonlinear time, less mathematic and relentless time in its orderly flow, but also casual, random, sudden as his god. Indeed, Kairos' hair is just in front, placed forward whilst his back is bald. When he presents himself, a unique, unrepeatable, irregular opportunity faces the subject and, if missed, taking it back will be impossible as his hair is just in front of his head. Carpe diem ... this famous 'carpe' refers to Kairos' hair, passing quickly, before our undecided eyes. For this uncertain reason, life is not what the "usual" pubis seems to offer: Eros' pleasure is ephemeral and it does not exist forever in this carnal temporality. So, the carioca designer is a kind of philosopher who addresses every glance from the model body to the bikini style and finally to her tattoo. My emotive reflection about the style is crossing through the three contiguous but not identical panoramas. And the last one, the tattoo, is offered as a novel (or a myth) that threatens the model's beauty: in every moment, the doll-like body may become a skeleton, a pile of dismembered bones without any connection. In my fantasy, this reflexive fashion designer updates the famous sentence of Horace in an original composition: he reinvents and accentuates the seduction of the unrepeatable and unstoppable caducity [2].

\section{Leopardi}

The poet of Recanati was also an essayist. In his "Operette Morali", Leopardi plays a philosophical dialogue between Fashion and Death, with a capital D because both are living beings. Fashion is what defies Death: she says they are sisters, claiming a deep 


\section{Current Trends in Fashion Technology \& Textile Engineering}

consanguineous affinity between them; she explains to the hasty Death that they are both daughters of transience.

Fashion: I am Fashion, your sister.

\section{Death: My sister?}

Fashion: Yes, don't you remember that were both born from transience?

Death: What I remember is that memory is my capital enemy.

She, the Fashion herself, cannot tolerate the life of a present dress, that's why she imagines how to eliminate it with the next trend. The fashion, better saying, Fashion, as a person without the article, cannot stand what is alive and present. She-Fashion looks at the impeccable design of a transience dress that is quiet obsolete when it is worn even for the first time: in the wrinkles of cloth, folds of flesh have already traced what makes it old, oldfashioned not in the sense of antiquate but in the sense of a recent one. Only the revival of vintage retains the buried items (hidden in attics, drawers and warehouses) and makes it rise again with a sense of chic. This Leopardi's affinity between Fashion and Death sparks reflections and phantasmagoria. Buying new clothes is not just a quirk of the consumption more or less encouraged by news agencies or advertising: it is a challenge to feel alive, to become life, to challenge through the new style the heaviness of the older one. What was just worn, is already assimilated as dead. There is something of theology in Fashion that challenges eternity with its creatures. One talks about Fashion creation, but in effect, they seem more like creatures: a concept, as some may remember, that challenges the only possible creativity, at least according to Christianity - the divine one... A Fashion show has something about agrarian archaic rituals that, at the end of winter, not only celebrated but favoured ('caused') spring's arrival and with it the rebirth of the floral nature, frozen by wintry season.

I say that our nature and common custom is to continually renew the world", Fashion explains. This generative cult is what makes Fashion and Death sisters: both make life reborn because both cut off what is alive; Leopardi clearly expressed the reason for this decisive act: "As if I were not immortal", Fashion proudly replies when Death threats to fetch her; and then Death, intrigued by this bold statement, questions more information to her unexpected sister. And Fashion's answer is brilliant [3].

Well, although it is not good manners to speak plainly, and though in France nobody speaks so as to be heard, yet, since we are sisters and need not stand on ceremony with each other, I'll speak as you wish. I say, then, that the tendency and operation common to us both is to be continually renewing the world. But whereas you have from the beginning aimed your efforts directly against the bodily constitutions and the lives of men, I am content to limit my operations to such things as their beards, their hair, their clothing, their furniture, their dwellings, and the like. Nevertheless, it is a fact that I have not failed at times to play men certain tricks not altogether unworthy to be compared to your own work; as, for example, boring men's ears, or lips, or noses, and lacerating them with the trinkets which I place therein; or scorching their bodies with hot irons, which I persuade them to apply to their persons by way of improving their beauty. Then again, I sometimes squeeze the heads of their children with ligatures and other appliances, rendering it obligatory that all the inhabitants of a country should have heads of the same shape, as I have ere now accomplished in America and Asia. I also cripple mankind with shoes too small for their feet, and stifle their respiration, and make their eyes nearly start out of their heads with tightly laced corsets, and many more follies of this kind. In short, I contrive to persuade the more ambitious of mortals daily to endure countless inconveniences, sometimes torture and mutilation, aye, and even death itself, for the love they bear toward me. I say nothing of the headaches, and colds, and catarrhs, and fevers of all sorts, quotidian, tertian, and quartan, which men contract through their worship of me, inasmuch as they are willing to shiver with cold or stifle with heat at my command, adopting the most preposterous kinds of clothing to please me, and perpetrating a thousand follies in my name, regardless of the consequences to themselves.

In short, all the previous practices and also the current ones (from tattooing to piercing, from the brand of fire and cranial or bone deformation) are anticipated and offered to Death's listening, and to all of us, who - still alive - are listening this Leopardi's lesson. At the beginning of XIX century (1824), for the poet fashionquestion is much more complex than contemporary common sense or simplistic sociology have been imagined: fashion as as conspicuous consumption, manipulated homologation or a caprice to be 'up-to-date'. Fashion emerging in the Western culture is not a simply dressing up, she first affirms herself globally, then is reworked locally and finally she presents glocal fragments, in which styles of different cultures are coexisting in a body assemblage made of fabrics, stitching, accessories, makeup, folds that the designer draws and each subject adapts or reworks to his/her own figure. Fashion incorporates the anxiety of changing an identity as one, a fixed and packaged identity, an ambivalent anxiety that characterizes a currently cultural dynamics toward continuous inventions under the sign of extreme diversities. Presenting Fashion as a whole is almost impossible: she has a multiverse that does not coincide with cool designers, pret-a-porter productions, discounts department stores, fake imitations, outlets with delayed brands, immortal vintage, individual recycling and etc. Fashion is immortal and metamorphic. Her destiny is to delete or to melt all that is solid because its immanent fate is mutation - where life pulses. She is immortal and polytheistic: there is no fashion god, but a brotherhood and competitive different deities who, each in their specificities, marks the future as philosophers were used to imagine few decades ago. If now philosophers are silent and rethinking only about their past history, with no desire or ability to interpret nor to change the present, it is because philosophy migrated to visual artists or street artists, fashion or sound designers. Zaha Hadid, Pan Sonic, Gaetano Pesce or Cindy Sherman emanate philosophy with their liberationist speeches, dissonant architectures, compulsive music, eccentric design, and mutant photos. They use a different alphabet from the one 
based on words: sensorial concepts that can conquer each person and anticipate what will be an innovative way of thinking about public/private body's aesthetics. This dichotomy is perhaps even questioned by a few daring designers. Some of these, Armani, Prada, Yves Saint Laurent, Dior, Vivienne Westwood and Alexander McQueen are to be placed on the same level of Zaha Hadid. They have their own philosophy [4].

So, in addition to the words written above the pubis, what does the model, or Fashion, says? The words are ambiguous and can be read in a traditional, almost obvious sense, and then in a more complex one. "Life based on the desire for sex, insolently shown in this catwalk, not only will never be forever like this, ever, but even now it is not so. In fact, what I show is the bright object of desire, a mix of bikini and vagina, but none will ever be yours, not now or never. So, please surrender, you male and female spectators to a vision at a distance that represses you to the same extent that excites. This object of desire is not to be given to you, not in the past, much less in your future. And then I, my own self, will never be like this to you nor to anybody else, even if I wear or show it. Never. That's why I assimilated myself to an amorphous doll, a half-living thing and a half death body. My seductive bodycorpse is dedicated to Madame Death, my inspiring aunt, because I know that, even incorporating at least for now a carnal Fashion, soon I will be rotting flesh and my caducity will be the triumph of my relentless sister. I am only a temporary appearance. I am here to affirm The Triumph of Fashion and Death. Buying a piece of fashion is booking death in advance. I said ...."

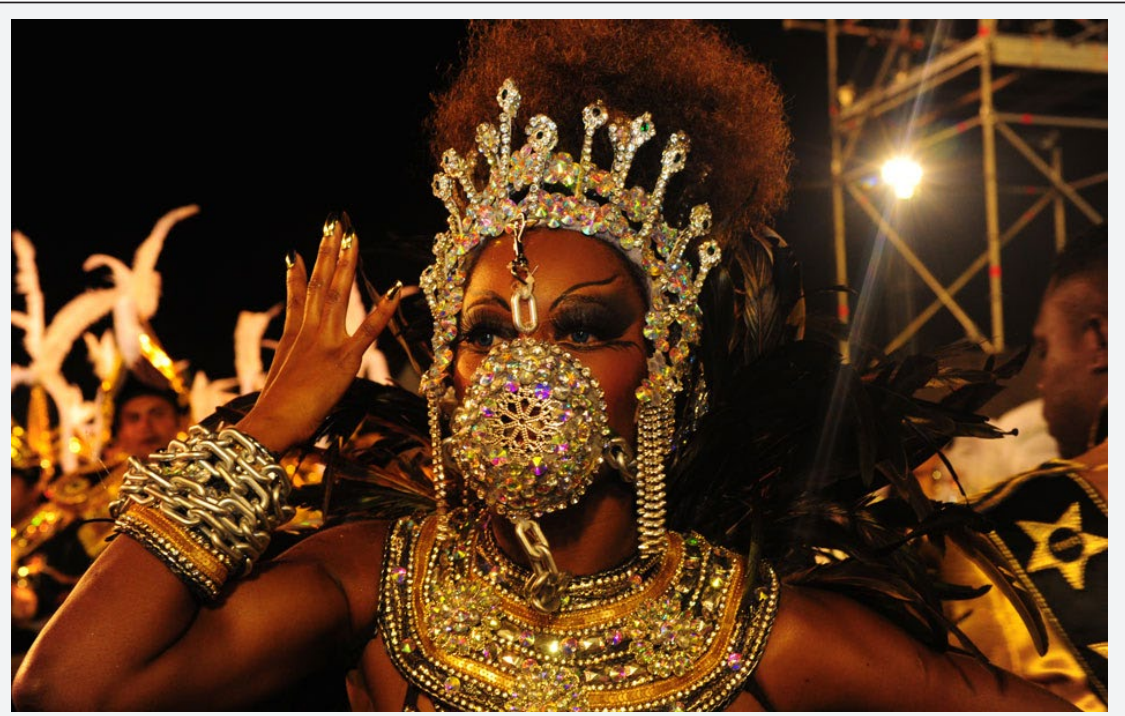

Figure 2: A passista (parader) in Rio de Janeiro's carnival (2012) and the homage to Anastasia: the muzzlebecame a jewel.

And that is what whispers the model, a caducous still life, a sublime beauty that is undoing the triumphant exposition of her body and writing in front of immobile spectators. Following my synchretic and fetish perspective, I find a "caducity" affinity with a Samuel Cirnansck's fashion show in Rio de Janeiro. Some models parade with their body covered with very traditional veils and fabrics. One of these stops with her hands on her hips as if challenging the viewers, showing bizarre fingers ringed with black cylinders that anticipate her menacing nails just as black. Has long been that accessories are no longer marginal, but they became as essential as the rest of the performance. At large, everything is an essential accessory in a catwalk. But here, a special accessory emerges: the mordaça de ferro (scold's bride). What impressed me most is to see that this parade takes place in Rio, probably near the church Nossa Senhora do Rosario dedicated to the Escrava Anastasia's ('Slave Anastasia') cult: every models wear a mordaça as an accessory, without expressing a single tribute nor even mentioning the tragic and symbolic story concerning the whole Afro-Brazilian movement or the Anastasia's liberationist role against slavery. Perhaps such a bizarre staging needs an interpretation. Of course, the key is the culture of fetishism that relentlessly expands in the different genres of contemporary sexualized communication. What was once a torture instrument, the gag, became now an accessory. This instrument owes its invention to the need of taming animals making them thus docile. Domesticated, in fact. The Western culture transferred this instrument from animals to human beings, especially heretics, a few centuries or perhaps a millennium later. These heretics were considered by the Catholic Inquisition not worth using the ultimate expression of humanity: the language (Figure 2).

Language is what differs animals from humans; hence, an heretic is not a human, being diminished to an animal state, having to be tamed and subordinated to a dominant 'specific' power that removes the right of the word whilst waiting for the final punishment. Giordano Bruno, philosopher and humanist, was burned alive in Campo de' Fiori in Rome with a muzzle on. In the same period - around XVI century - another phenomenon changes Western political and cultural geography: the conquest (or the so called "descobrimento") of America with its consequent imperative of imported slaves, whilst the native populations preferred to die than to work in such conditions. In this way, the rebel slaves coming from Africa have their mouth gagged, to show publicly that any slave was an animal, that s/he had to work in 
a domesticated way, eventually copulate and eat to survive. Toni Morrison - the great African-American writer - recreates in her novel Beloved what a person with a piece of iron in his teeth for 12-15 hours a day would feel. A madness withheld and violated by the capillaries of one's reddened eyes, from the slow drool clotted on one's lips, the heavy breathing and an explosive and diverted anger.

He wants me to ask him about what it is like for him - about how offended the tongue is, held down by iron, how the need to spit is so deep you cry for it. She already knew about it, had seen it time after time in the place before Sweet Home. Men, boys, little girls, women. The wildness that shot up into the eye the moment the lips were yanked back. Days after it was taken out, goose fat was rubbed on the corners of the mouth but nothing to soothe the tongue or take the wildness out of the eye" (Morrison, 2004). And then, what does it means a fashion parade with this accessory inside the model mouth, in a country that last abolished slavery and in a city where Anastasia is venerated as a saint? (Figure 3).

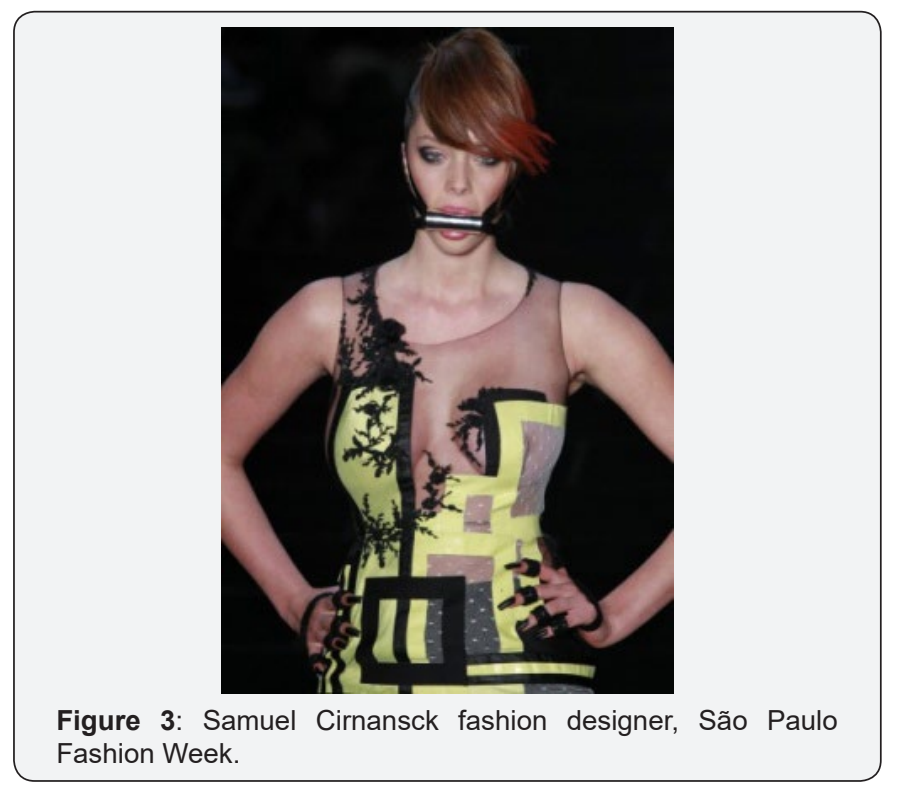

The symbolic power of the slaver or heretic iron bit is decaying, it evaporates into a simple code through a de-symbolized process, an exciting sign is ambiguously parading between political amnesia and liberationist pleasure. A kind of $\mathrm{s} / \mathrm{m}$ performance offers an apparent feminine submission playing with symbols and signs as gadget to be offered as a dark desire to the audience that may imagine some quiet private games. So, this model, as a Fashion's amnestic body, fractures the historical link with the slavery past, cancels the force of the oppressive symbols, displays a seductive excess that dominates by showing herself as submissive ruling woman. And it is precisely this apparent submission that proclaims, in contrast, the triumph of fetishism. I'm sure that the visual proliferation of fetish current meanings expresses the subtle connection between Fashion and Death (Canevacci, 2015). In Leopardi determinant dialogue, visual fetishism is the missing link that manifests the deep sisterhood between these two restless Ladies through the impudent mordaça de ferro. Perhaps, Anastasia will not be scandalized by this tampering, maybe she perceives that - through the symbolic emptying of what was her instrument of torture - justice is finally served. Perhaps now Anastasia can finally smile and show those magnificent white teeth and her carnal lips that made very jealous the wife of the slave master, a wife in turn slave of a jealousy based on her classist privilege (Figure 4).

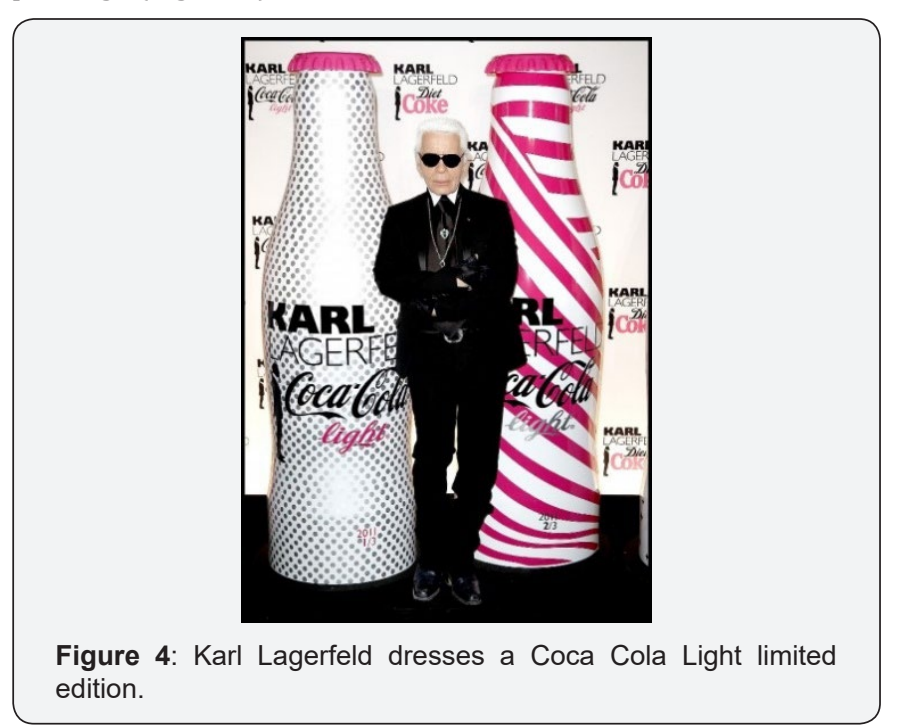

Karl Lagerfeld is a famous fashion designer. The obvious decision to add him to a research project on syncretism comes from this photo and a more general hypothesis: new visual fetishisms have in cultural syncretisms one of the potential applications in the field between the unstable and mutant zone of fashion and art. Visual fetishisms and cultural syncretisms develop the potentialiality of wandering arts. These are the ones oscillating among different genres and with the tendency to suppress boundaries. Lagerfeld designs clothes for humans; designers dress things, objects and goods. Coca-Cola has in its body, that is, in the body of the bottle and in its written vintage, its brand and style, perhaps even its taste. Coca-Cola's feminine design form has been long discussed. Why is a sophisticated and dandy stylist as Lagerfeld entrusted to create the new look of the brand?

The first reflexion is simple: the body of the bottle is a bodycorpse, meaning that it transits between a living body and a dead corpse. This tendency of visual fetishisms distorts and amplifies the traditional analysis on the "nature" of fetish objects. Accordingly, this ambiguous drinkable body is always in need for new clothing and has to find temporary solutions between tradition and innovation. Examples are indeed endless on this subject. The interesting point here is that most classic products of mass culture do intersect an equally classic elite's designer. The super fetish Karl. The mentioned dissolution of boundaries between genres is a gray area (or a brilliant one) where oscillating syncretism flows. To achieve a fit-for-purpose result, syncretisms hybridizes with fetishisms [5].

Whilst observing the picture with some sort of careful obsession, a few obvious points came up: the bottles are actually two, perhaps a male and a female version. Both are Coca Cola 


\section{Current Trends in Fashion Technology \& Textile Engineering}

Light written with the traditional font but with different colour, so conscious and faithful consumers can even compute the calories swallowed from a glass of a coke. Above the drinkable brand, there is the designer brand: KARL in bold letters and LAGERFELD in thin ones. Below, the year of production is shown, like a vintage wine: $2011-1 / 3 ; 2 / 3$. Looking with more attention, it is possible to discover on one side a black silhouette observing the result. Widening the perspective on methodological fetishism, my glance understands that the bottles are three: he, Lagerfeld, is the third bottle, a good between the goods, his value added is the fetish art he manages in order to incorporate himself into the two bottles. His dark identity transits between the polka dot and the sinusoidal striped dress on the bottles. It is well-known that Lagerfeld always dresses in the same way. Paradoxically, his diversified styles occurs whilst he wears always the same dress. A man in black with an eternal dandy collar, sacred accessories, impenetrable glasses as much as his face-mask is. Clearly, Karl Lagerfeld is also the hyphen '-' where syncretic fetishisms flows. $\mathrm{He}$ is the body-corpse creator. He objectifies himself as the third bottle, as much as he enlivens the other two with their glamorous clothes. The Coca-Cola bottles come to life and can be dressed like any human being, only because he assimilates himself to a living commodities. Observing a little bit closer, and even better, being a little bit naughty, one may notice that his body rests on one foot, in this way his silhouette creates a slight curve that accompanies both bottles' sensual curve (the sexiest coke hips). Finally, Lagerfeld's crossed arms assimilate even more him to the two 'persons' on his side. Everybody lack of arms.

These three beings are perhaps trans-gender. The final result of this fetishism/syncretism crossing reaches the sex-game: visual goods, with their hyper-sexed design that spreads and mixes organic and inorganic, nature and culture, mass consumption and elite's art, are alive because they transit between identities, styles and beings (Figure 5). Belém is a city on the source of the Amazon River. As all of Brazil, Belém is changing fast, the co-presence of different codes is even more enlarged than the 'normal'. The city's markets are an excess of colours and flavours, as its craftsmanship and, off the coast, the large island of Marajó where traces of pottery and other products of great beauty were left by a refined ancient culture. Whilst casually visiting a popular market on a large, beautiful and messy square, I was drawn to a mannequin. Clearly, this was a mannequin of Chinese origin, as nearly all popular ones everywhere, not only in Brazil. I believe the production of these beings have really invaded the world. Yet, here I am, blocked by astonishment looking at her. I reckon it is a spontaneous work of art in which, once again, the 'objective' fetishism built into each mannequin is crossed and augmented by some sort of Sino-Brazilian syncretism. Colour is the first thing: a well-defined orange I have never ever seen on any another mannequin or person for the matter, Chinese or Brazilian. A mutant being for sure, I reckon. Then, a missing arm, the left one, leaving an emptiness that looks like a round eye-mouth hollow yawning its surroundings [6].

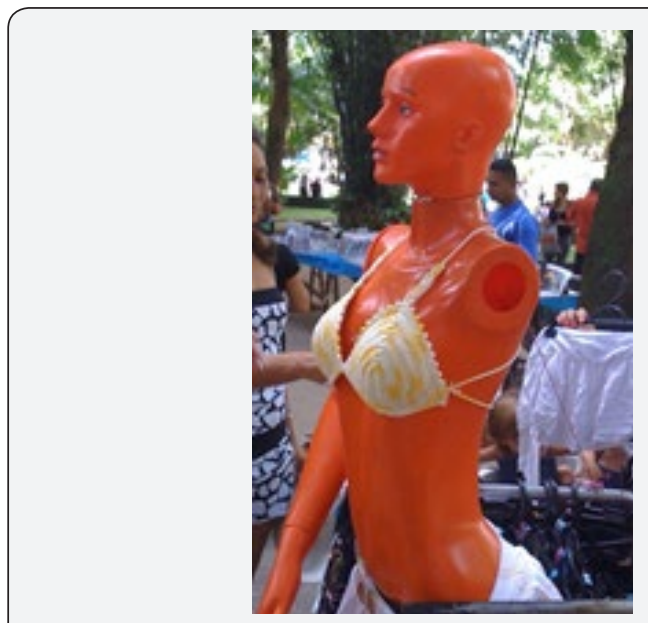

Figure 5: Body-corpse.

The most disturbing 'thing' is her head: clearly detached, perhaps lacking internal support, like the cervical one, properly connecting it to the torso. Right there in the usual spot, slightly tilted though, looking like a guillotined head that has been put back into place simply to enhance the show. A baldhead with such a smooth skull looking like no wig would remain seated there. Finally, the eyes: the mannequin's eyes and even the eyebrows expressed infinite sadness, something I have never seen in other mannequins, usually displaying a dull face, rather expressionless. Here, however, the pain is obvious, something terrible must have happened to this mannequin; of course, the arm is missing; the head, detached; all hair is long gone; but it is not only that. Mannequins are used to such misfortunes. This one, however, must have suffered a recent experience that printed in her physiognomy a sense of anguish, anxiety, perhaps even horror due an encounter or even a terrible fate. Eyebrows and lips are bent down, its eyes troubled and plain sad.

\section{Dismembered Body}

Maybe this mannequin feels it might be a work of art, living art, jetting globally around galleries and museums; perhaps it feels its destiny, created by an artist or artisan, is unique. Maybe it is not like the other mannequins, always a bit vulgar and yet, ever so identical. This one is unique. It is the only one expressing these unusual colours and a dismembered body. Certainly, the mannequin cannot exactly recall how it happens to land there, in that beautiful square, but surely, not worthy of her status. Her memory is confused. Clearly, a princess she is. Her extreme nobility is expressed by her behaviour, which continues to be dignifying even in such disastrous and inadequate situation.

I understand very well what disturbs her more than anything: it is the bra she wears. Really ugly, she knows, the mannequin feels it. How is that possible that her person is forced to expose herself with such an ... awful object. Yes, the bra is handmade, but is not gracious, it is too wide, with three strings attaching behind. Who would buy a similar object? And how long was she forced to wear that cover, thankfully other garments cover her bottoms, also not 
appropriate but eventually bearable. No, not the bra, though. If the mannequin had both arms and a less stiff neck, she might have been able to take it off and proudly show her beautiful orange breasts. But she cannot. And her dismay increases, becoming rather uncontrollable, reaching out and making even me worried. would have loved to buy that orange woman-mannequin. I thought about it for a long time whilst going around her in circles. Truth is, this was an encounter with a well-lived work of art, one that has travelled and suffered, that resists despite or because of her semiabandoned condition. She should really be displayed again, as in her recent past, in a wandering art gallery.

Her beauty is vague. Vague is the only appropriate adjective to her bodily condition. The madam of that outdoor stall, seen in the background, was an elegant woman, mastering her movements, organizer of her goods. What kept me from asking her about the price of the orange mannequin, was the idea of travelling by plane with her. I was embarrassed with the idea of having she sat next to me, whilst departing to São Paulo and the other travellers giggling. I was an incompetent or a coward. I abandoned setting she free from her current fate, saddened as the expression on her face, only because of my timid hypocrisy. And the mannequin, so shiny and sweaty, dismembered and erected, so sad and resolute, royal, would lie abandoned who knows where. She is a spontaneous work of art, mixing and exposing all the syncretic fetishism of its body-corpse. A mannequin, travelled from different continents and cultures, incorporating the ambiguous desire of a being that is still alive even in most disastrous situations. For me, it / she is more attractive and desirable than the other three hyper-fetish human bottles previously observed. She is alive and vague.

My final cut on fashion: Madame Fashion is and even more will be ubiquitous, syncretic, plyphonic, meta-fetishit and metamorphic

\section{References}

1. Hatje Cantz (2005) Hybridentities, in Hybrid-Living in Paradox. Ars Electronica Linz.

2. (2008) Body-corpse: extreme youth cultures for exterminated arts, in The Young Aggressive. Refractory Character of Contemporary Art in Russia, Musashino Art University, Japan.

3. Stefano Giacchetti (2015) An Astonished Facticity: Toward a Metafetishist Ethnography, in Critical Theory and the Challenge of Praxis, Ashgate Publishing, Farnham, UK.

4. Gilroy P, Meltemi (2003) The Black Atlantic. Roma.

5. Leopardi G (1960) Dialogo della Moda e della Morte, Milano, Rizzoli.

6. Morrison T, Frassinelli (1988) Amatissima, Piacenza, Italy.

\section{Your next submission with Juniper Publishers will reach you the below assets}

- Quality Editorial service

- Swift Peer Review

- Reprints availability

- E-prints Service

- Manuscript Podcast for convenient understanding

- Global attainment for your research

- Manuscript accessibility in different formats

( Pdf, E-pub, Full Text, Audio)

- Unceasing customer service

Track the below URL for one-step submission https://juniperpublishers.com/online-submission.php 